\title{
The Chikyu: Meeting the Challenges of a New Scientific Drilling Era
}

\section{by Asahiko Taira}

The City of Nagasaki, at the western end of the Island of Kyushu, Japan, is an exotic place. During the Edo era from the 17th to 19th century, Japan closed its doors to the outside world and Nagasaki was designated as the sole gate to Dutch and Chinese traders. As a result, the city brewed a unique cultural flavor with a blend of eastern and western heritages.
Among the citizens of Nagasaki, a ship with a very high tower, especially visible with night illumination at Mitsubishi Heavy Industry Ltd.'s Koyagi Works, has been a topic of daily conversation. Despite the city's long history of shipbuilding, they have rarely seen such a unique ship. The ship's name is Chikyu (meaning Earth in Japanese), and it is

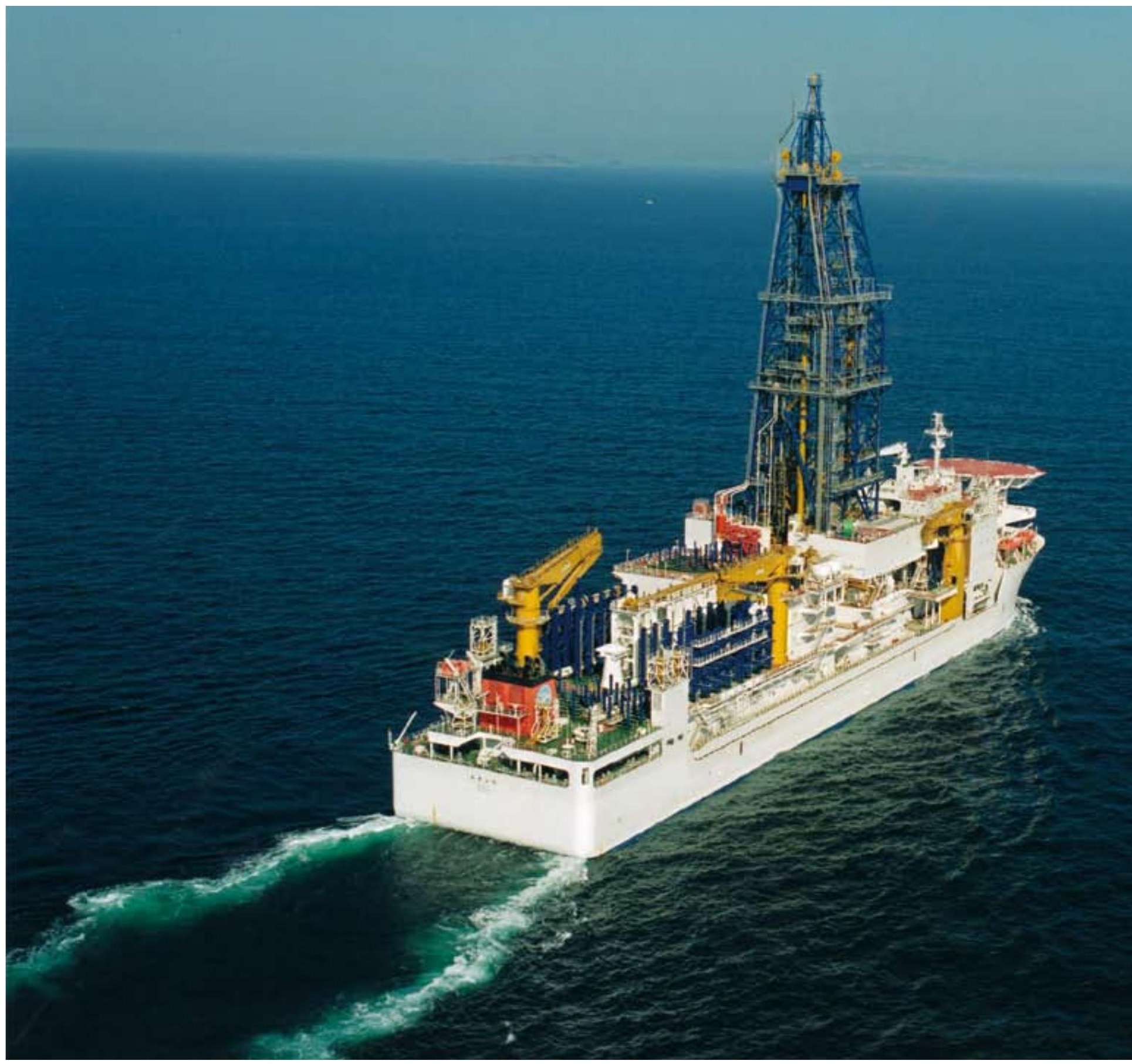


the first riser-equipped scientific drilling vessel ever built, with a record height of $122 \mathrm{~m}$ from the bottom of the hull to the top of the derrick (http://www.jamstec.go.jp/jamstec-e/ cdex/earth/). The ship is truly a blend of worldwide technologies. For example, the hull, engines, and dynamic positioning system were manufactured in Japan, the drilling facilities came mostly from Europe, and the riser pipes were made in the U.S.A. Much like Nagasaki, this ship is a blend of international heritages.

The plan for building a new scientific deep-sea drilling vessel in Japan started more than ten years ago. The Japan Agency for Marine-Earth Science and Technology (JAMSTEC) took leadership for this project, and following numerous domestic and international meetings and workshops, construction started in April 2001. The launching ceremony was conducted in January 2002 at Mitsui Shipbuilding Co.'s Tamano Shipyard. The ship then sailed to Nagasaki for further outfitting and underwent the final phases of commissioning and testing of its various systems during mid 2005.

The Chikyu is designed to drill deeper than ever before beneath the deep-sea floor. The target was set to drill to $7000 \mathrm{~m}$, in water depths initially up to $2500 \mathrm{~m}$, eventually up to $4000 \mathrm{~m}$. To ensure borehole stability, remove rock cuttings, and prevent gas or water blow-outs, heavy, muddy drilling fluid must be circulated through the borehole between the ship and the bottom end of the drillbit. Deployment of riser pipes that enable the confined circulation of this heavy mud is the key technology of the Chikyu. The ship is required to remain stationary for a long time at sea against wind, waves, and currents. This stability is achieved by six powerful computer-controlled thrusters with 360-degree, screw-axis rotation capability. Robotic and automated drillpipe handling systems ensure a safe and efficient working environment.

The Chikyu houses advanced and comprehensive scientific research facilities. Four stories of laboratories and living quarters with an array of tools and equipment provide space for fifty scientists and technical support staff. With synergy between state-of-the-art technology and the enthusiasm of researchers and engineers, the Chikyu is prepared to push the frontiers of scientific drilling into the deep unexplored biosphere, into depths where mantle rocks deform, into the seismogenic zone where strain energy for mega-earthquakes responsible for huge tsunamis is accumulated, and where the unread records of Earth's history are archived.

After the delivery in late July of this year, JAMSTEC's Center for Deep Earth Exploration (CDEX) has taken responsibility for ship operations. The current plan calls for two years of testing and training offshore of northeastern Japan; the Chikyu operations will then be fully incorporated into the Integrated Ocean Drilling Program (IODP) in late 2007. The voyage of the dilling vessel Chikyu, seeking out and expanding new frontiers in science, technology, and international collaboration, is about to begin.

\section{Author}

Asahiko Taira, Director-General, Center for Deep Earth Exploration, Japan Agency for Marine-Earth Science and Technology, CDEX OD21 Program Department, 2-15 Natsushima-cho, Yokosuka, Japan 237-0061, e-mail: ataira@jamstec.go.jp

\section{Figure Credit}

Photo courtesy of Japan Agency for Marine-Earth Science and Technology (JAMSTEC). 